\title{
Comparison of the Antioxidant Activities of Various Processed Fruits and Vegetables in APAP-induced Oxidative Stress in BALB/c Mice
}

\author{
Evelyn Saba $^{1, *}$, Yuan Yee Lee ${ }^{1, *}$, Minki Kim ${ }^{1, *}$, Hyun-Kyoung Kim ${ }^{2, * *}$ and Man Hee Rhee ${ }^{1, *, * *}$ \\ ${ }^{1}$ Laboratory of Physiology and Cell Signaling, College of Veterinary Medicine, \\ Kyungpook National University, Daegu 41566, Korea \\ ${ }^{2}$ Department of Food Science and Engineering, Seowon University, Chungbuk 28674, Korea
}

\begin{abstract}
Research has established a strong connection between a diet rich in antioxidants and a decreased incidence of cardiovascular disease and cancer. These diets prominently feature fruits and vegetables containing high amounts of vitamins A, B, C and E, carotenoids, and minerals. Different processing conditions for these foods can alter their nutrient complement and potency. This study compared the antioxidant properties of a range of processed fruits and vegetables to see which yielded the highest level of antioxidant activity. We used an acetaminophen-induced oxidative stress mouse model to evaluate the antioxidant effects of extracts of processed apple, pear, carrot, cabbage, broccoli, and radish. Our results showed that the administration of these fruits decreased the expression of oxidative stress indicators such as ALT, AST, catalase, superoxide dismutase, GPx, and 8-OHdG. They also significantly protected mice livers from APAP-induced damage, as shown by histological evaluation. Our results have demonstrated the positive effects of processed fruits and vegetables in a mouse model of oxidative stress.
\end{abstract}

Key Words: Antioxidant activity, Vegetables, Fruits, Acetaminophen, Mice

\section{INTRODUCTION}

A great deal of epidemiological evidence supports the connection between diets rich in fruits and vegetables and a reduced risk of cardiovascular disease and cancer (Dauchet et al., 2009; Casas et al., 2018). Oxidation occurs in the presence of free radicals, and studies have shown that free radicals cause oxidative damage to different molecules, such as lipids, proteins, and nucleic acids and are thus involved in the development of certain degenerative and chronic diseases (Lobo et al., 2010; Boeing et al., 2012). Antioxidant compounds, both natural and synthetic, can neutralize free radicals and help prevent certain diseases, such as cancer, cataracts, cerebral pathologies, and rheumatoid arthritis (Lobo et al., 2010; Kasote et al., 2015).

Fruits and vegetables contain antioxidant compounds such as vitamins $\mathrm{C}$ and $\mathrm{E}$ and carotenoids, and recent work has revealed the presence of polyphenol compounds in fruits and vegetables such as flavonoids that also contribute beneficial effects (Pandey and Rizvi, 2009; Alkadi, 2018; Lutz et al., 2019). Besides polyphenols, many other compounds present in fruits and vegetables assist in their antioxidant activity. For example apple polyphenol phloretin had been found to

Received: June 7, 2019 / Revised: June 24, 2019 / Accepted: July 4, 2019

* Graduate student, ${ }^{* *}$ Professor.

${ }^{\dagger}$ Corresponding author: Man Hee Rhee. Laboratory of Physiology and Cell Signaling, College of Veterinary Medicine, Kyungpook National University, Daegu 41566, Korea.

Tel: +82-53-950-5967, Fax: +82-53-950-5955, e-mail: rheemh@knu.ac.kr

(C) The Korean Society for Biomedical Laboratory Sciences. All rights reserved.

(c) This is an Open Access article distributed under the terms of the Creative Commons Attribution Non-Commercial License (http://creativecommons.org/licenses/by-nc/3.0/) which permits unrestricted non-commercial use, distribution, and reproduction in any medium, provided the original work is properly cited. 
suppress the PI3K/AKT pathway that is activated as a result of oxidative stress (Liu et al., 2016). Epidemiological studies have found a relationship between plant antioxidants and the amelioration of certain chronic diseases (Kasote et al., 2015; Kumar et al., 2015). Ascorbic acid, a major antioxidant, is widely consumed in the form of tablets, syrups, and other supplemental forms. Certain studies, however, have suggested that supplemental vitamin $\mathrm{C}$ intake might instead enhance its pro-oxidant properties (Leonard et al., 2002). Scientific communities maintain that the consumption of natural foods remains the best way to increase antioxidant intake, and research into processing methods that preserve the maximum amount of nutrients therein is ongoing.

In our study, we investigated the antioxidant properties of processed apple, pear, carrot, cabbage, broccoli, and radish extracts in vivo in an acetaminophen (APAP)-induced oxidative stress mouse model. Our results strongly suggest that the administration of these extracts decreased levels of plasma ALT, AST, catalase, SOD, GPx and 8-OHdG, and protected the mice livers from the harmful effects of APAP. Overall, these findings indicate that the processing of these fruits and vegetables has not reduced their antioxidant effects.

\section{MATERIALS AND METHODS}

\section{Extract preparation}

The samples Malus Domestica (apple), Pyrus Communis L. (pear), Daucus carota L. (carrot), Brassica oleracea var. (broccoli), Brassica oleracea var. capitata (cabbage) and Raphanus sativus L. (radish) were agricultural products grown in South Korea and locally purchased from traditional market. The samples were washed; then cut into uniform shapes of $0.5 \mathrm{~cm} \times 0.5 \mathrm{~cm} \times 0.5 \mathrm{~cm}$, freeze-dried, sealed dry to keep away from moisture and stored in $-70^{\circ} \mathrm{C}$. Raw samples underwent heat treatment using an apparatus, with a pressure of $10 \mathrm{~kg} / \mathrm{cm}^{2}$ (Jusco, Seoul, South Korea). The samples were placed in the inner compartment container, and water was added in the outer compartment of the container. The apparatus was heated up according to predetermined temperature and time $\left(140 \sim 150^{\circ} \mathrm{C}\right.$ for 6 hours $)$ to prevent carbonization of samples from direct heat. Samples were weighed and were dissolved in deuterium-depleted water
(DDW) for oral administration at a dose of $500 \mathrm{mg} / \mathrm{kg}$. The dosages of samples were determined in accordance with some previously reported studies on the effects of the components of fruits and vegetables in in vivo oxidative stress models (Singh et al., 2012; Syed et al., 2014; Sharma et al., 2016).

\section{Estimation of the antioxidant activity of processed fruits and vegetables}

We estimated the antioxidant properties of the processed vegetables and plants samples in our previously reported data (Lee et al., 2018). Mainly the antioxidant effects of the fruits and vegetables are due to the abundant polyphenols, flavonoids, anthocyanins, phytoestrogens, carotenoids (Miller et al., 2000).

\section{Experimental animals and sample administration}

Male BALB/c mice, 6 to 8 weeks old and weighing between 19 and $22 \mathrm{~g}$ were purchased from Charles River, Orient Biotechnology, Gyeonggi-do, South Korea. Mice were housed in a specific-pathogen-free (SPF) barrier facility at $21 \pm 2{ }^{\circ} \mathrm{C}$ with a relative humidity of $60 \pm 10 \%$ under a $12 \mathrm{~h}$ light and dark cycle. Food and water were provided ad libitum. All animal care and experimental procedures were carried out in accordance with internationally accepted guidelines on the use of laboratory animals, and study protocols were approved by the Animal Care Committee (IACUC) of the College of Veterinary Medicine, Kyungpook National University, Daegu, South Korea. Mice were divided into 9 groups, with each group containing six animals. Group 1 was the control group with vehicle treatment only; Group 2 was the APAP-challenged-only group, receiving an intraperitoneal (IP) injection of $400 \mathrm{mg} / \mathrm{kg}$ of acetaminophen in a single dose; Group 3 was the positive control $\mathrm{N}$-acetylcysteine (NAC) group, receiving $75 \mathrm{mg} / \mathrm{kg}$ thereof orally for each day for seven days as previously reported (James et al., 2003); Group 4 was the processed apple group, Group 5 was the processed pear group, Group 6 was the processed carrot group, Group 7 was the processed broccoli group, Group 8 was the processed cabbage group, and Group 9 was the processed radish group. Animals in groups 4 through 9 were fed their respective extracts for 7 days and, with the last at $2 \mathrm{~h}$ 
after last sample administration. APAP was injected into all mice except Group 1, the control group. Twenty-four hours after the last administration, blood and liver tissues were harvested after euthanization of animals by $\mathrm{CO}_{2}$ asphyxiation, for estimation of different oxidative parameters. For serum preparation, blood from mice was carefully withdrawn and put in the Eppendorf tubes without anticoagulant for about $1 \mathrm{~h}$. Then the serum was extracted and put in new Eppendorf tubes and centrifuged at $1,000 \sim 2,000 \mathrm{~g}$ for $10 \mathrm{~min}$ at $4{ }^{\circ} \mathrm{C}$ and later stored at $-20^{\circ} \mathrm{C}$ till further use.

\section{Assessment of serum 8-hydroxy-2'-deoxyguanosine (8- OHdG) levels}

For $8-\mathrm{OHdG}$ measurement and biochemical analysis, blood samples were collected from mice under isoflurane respiratory anesthesia and placed in serum tubes. An 8OHdG assay kit (Cayman Chemical, Michigan, USA) was used to measure 8-OHdG levels. The content was measured based on the competition of 8-OHdG and AChE enzymelabeled 8-OHdG for 8-OHdG monoclonal antibody.

\section{Preparation of liver homogenate}

After euthanasia, liver tissue was immediately extracted and stored in physiological saline on ice until homogenization. A $10 \mathrm{mmol}$ Tris- $\mathrm{HCl}$ and $1 \mathrm{mmol}$ ethylenediaminetetraacetic acid (EDTA, pH 7.4) buffer was used for homogenization. Whole liver tissues were placed in $20 \mathrm{~mL}$ of homogenization buffer, and then $10 \%$ homogenate was prepared relative to liver weight. After centrifugation at 1,500 rpm for $30 \mathrm{~min}$ at $4{ }^{\circ} \mathrm{C}$, the supernatant was separated and stored at $-80^{\circ} \mathrm{C}$ until further analysis.

\section{Measurement of antioxidant enzyme levels in liver tissue}

Antioxidant enzyme activity was analyzed using specific enzyme assay kits (Cayman Chemical, Michigan, USA). Superoxide dismutase (SOD) activity $(\mathrm{Cu} / \mathrm{Zn}, \mathrm{Mn}$, and FeSOD) was measured by diluting samples to 1:1,000. Catalase (CAT) activity was measured by 4-amino-3-hydrazino5-mercapto-1,2,4-triazole (Purpald), in a sample diluted to 1:1,000. Glutathione peroxidase (GPx) assay was performed in the presence of glutathione (GSH) and oxidized glutathione (GSSG), and GPx activity was evaluated by differences in absorbance values at different NADPH levels with a sample dilution of 1:20.

\section{Evaluation of liver damage by serum biochemical analysis}

Blood levels of aspartate aminotransferase (AST) and alanine aminotransferase (ALT) in mice were measured using specialized kits according to manufacturer's instructions (Cayman Chemicals, MI, USA).

\section{Hematoxylin and eosin staining of liver tissue}

Liver tissue was harvested from mice after euthanasia and processed for paraffin embedding, slicing, and hematoxylin and eosin (H\&E) staining.

\section{Statistical analysis}

Data are presented as mean \pm SEM. One-way ANOVA and Dunnett's tests were applied for the statistical evaluation of the data. A $P$-value of less than 0.05 was considered statistically significant. Respective significance marks are described in the figure legends.

\section{RESULTS AND DISCUSSION}

\section{Amelioration of ALT and AST activity by fruit and vegetable extracts}

ALT is a transaminase enzyme that catalyzes the two parts of the alanine cycle, and is found in plasma and various body tissues and most commonly in the liver. Serum ALT and AST and their ratio (AST/ALT ratio) are biomarkers of liver health. ALT is usually measured as part of a diagnostic evaluation of hepatocellular injury (Huang et al., 2006; McGill, 2016). As shown in Fig. 1A, while all extracts reduced the levels of ALT in the serum of APAP mice, the strongest results were for the processed apple and radish extracts. Serum AST levels were most prominently reduced by apple and cabbage extracts (Fig. 1B). The underlying mechanisms mainly involve enhancing anti-oxidative defense enzymes by mediating nuclear factor erythroid 2-related factor 2 (Nrf2)/cytochrome P450 2E1 (CYP2E1) expression, decreasing inflammation by alleviation of mitogen-activated protein kinase (MAPK)/nuclear factor kappaB (NF- $\mathrm{kB})$ signaling pathways and suppressing apoptosis through regulating 
(A)

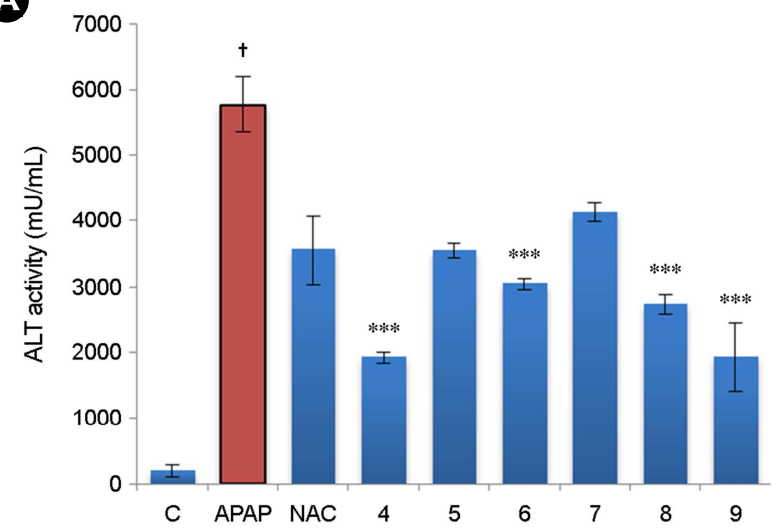

B

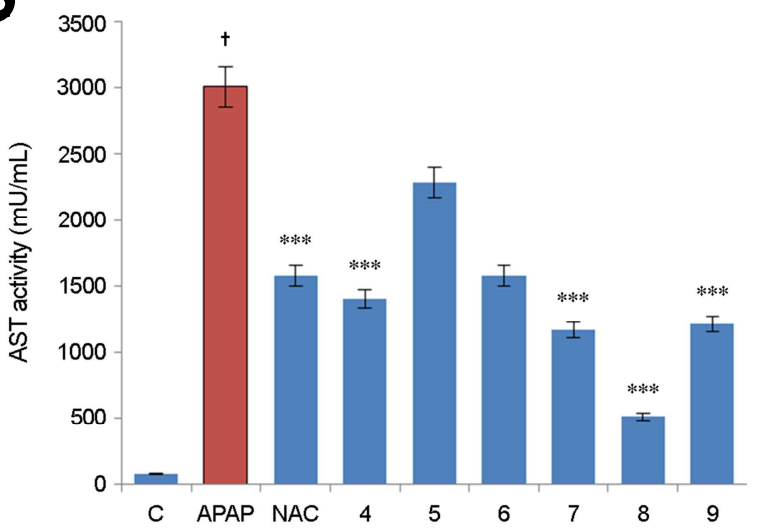

Fig. 1. (A) Alanine aminotransferase (ALT) and (B) aspartate transaminase (AST) levels in the serum. $\dagger$ indicates $P<0.05$ as compared to the control group, *** indicates $P<0.001$ compared to acetaminophen, and T indicates $P<0.01$ compared to NAC (positive control). 4 , apple; 5 , pear; 6 , carrot; 7 , broccoli; 8 , cabbage; 9 , radish.

B-cell lymphoma 2 (Bcl-2)/protein kinase B (AKT)/caspase expression (Li et al., 2018).

\section{Restoration of SOD, GPx and catalase activity and reduction of 8-OHdG by fruit and vegetable extracts}

Superoxide dismutase (SOD) is an enzyme that alternately catalyzes the dismutation (partitioning) of the superoxide $\mathrm{O}_{2}{ }^{-}$radical into either molecular oxygen $\left(\mathrm{O}_{2}\right)$ or hydrogen peroxide $\left(\mathrm{H}_{2} \mathrm{O}_{2}\right)$. It is produced as a by-product of oxygen metabolism and, if not regulated, can cause cell damage. SOD is an important antioxidant for all living cells exposed to oxygen (Younus, 2018). As can be seen in Fig. 2A, APAP administration caused SOD levels to decrease significantly in comparison to the control group. Processed apple, carrot, and cabbage extract administration restored SOD levels as compared to the APAP group.

Glutathione peroxidase (GPx) is the general name for an enzyme family with peroxidase activity whose main biological role is to protect the organism from oxidative damage. Glutathione peroxidase reduces lipid hydroperoxides to their corresponding alcohols and free hydrogen peroxide to water (Lubos et al., 2011). As shown in Fig. 2B, GPx levels were predominantly decreased in the APAP group, while processed apple and broccoli extracts restored levels of this enzyme as compared to the APAP group.

Catalase (CAT) is a common enzyme found in nearly all living aerobic organisms that catalyzes the decomposition of hydrogen peroxide into water and oxygen. It is important for protecting the cell from oxidative damage via reactive oxygen species (ROS). Hydrogen peroxide is a harmful byproduct of many normal metabolic processes and must be quickly converted into other, less dangerous substances to prevent damage to cells and tissues. Cells produce catalase to rapidly catalyze the decomposition of hydrogen peroxide into less-reactive gaseous oxygen and water molecules (Northrop, 1925; Glorieux and Calderon, 2017). In Fig. 2C, it can be seen that the CAT activity that was significantly decreased in the APAP group was increased in the processed apple and cabbage groups when compared to APAP and positive controls.

8-oxo-2'-deoxyguanosine (8-OHdG) is an oxidized derivative of deoxyguanosine and is one of the major products of DNA oxidation. Concentrations of $8-\mathrm{OHdG}$ within a cell are a measurement of oxidative stress (Valavanidis et al., 2009). As can be seen in Fig. 2D, 8-OHdG levels that were extremely elevated in the APAP oxidative stress group were reduced significantly by processed apple and broccoli when compared with the APAP and NAC (positive control) groups.

\section{Effects of fruit and vegetable extracts on APAP-induced hepatic damage}

Liver tissues from all mice were harvested, and their morphology was examined histologically to evaluate changes induced by APAP and whether extracts treatment had affected 
(A)

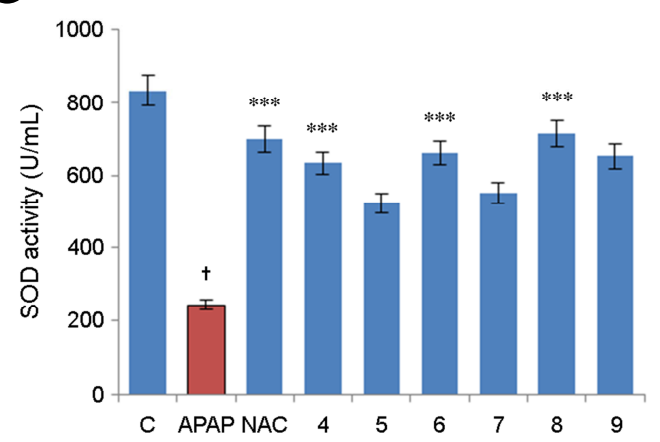

C

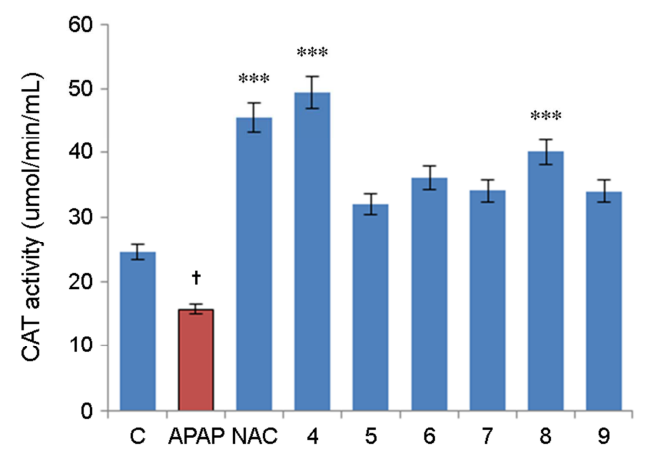

B

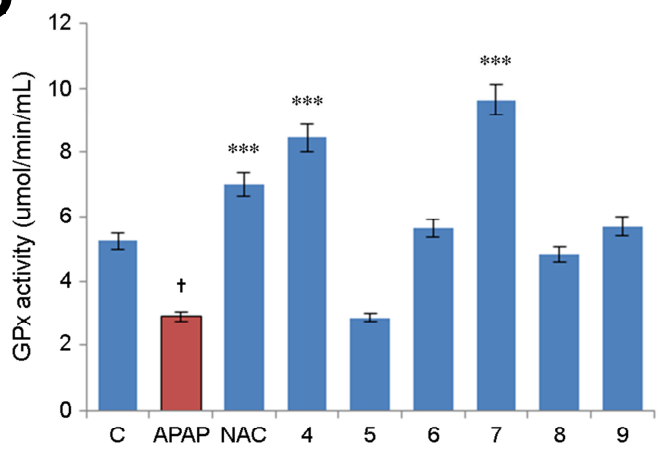

(D)

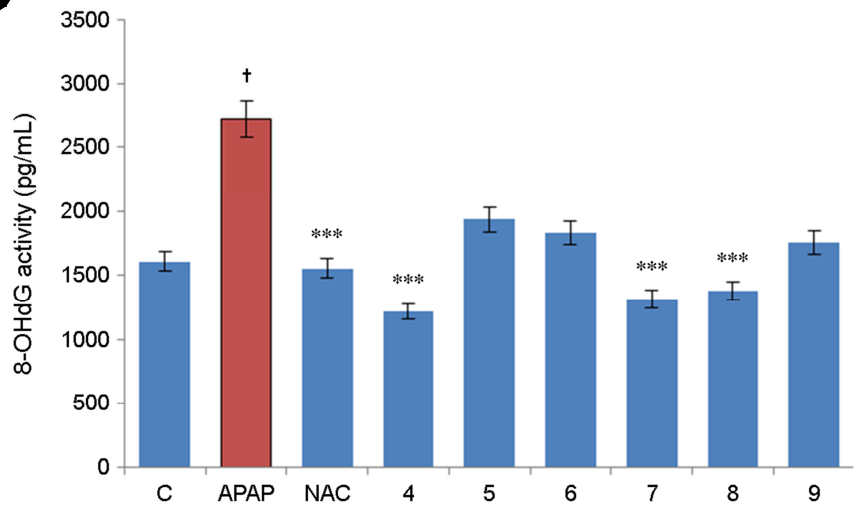

Fig. 2. (A) Superoxide dismutase (SOD), (B) glutathione peroxidase (GPx) and (C) catalase activity (CAT) and (D) 8-oxo-2'-dexoxyguanosine (8-OHdG) levels in the serum of mice in the serum of mice. $\dagger$ indicates $P<0.05$ compared to control, *** indicates $P<0.001$ compared to acetaminophen, and T indicates $P<0.01$ compared to NAC (positive control). 4, apple; 5, pear; 6, carrot; 7, broccoli; 8, cabbage; 9 , radish.
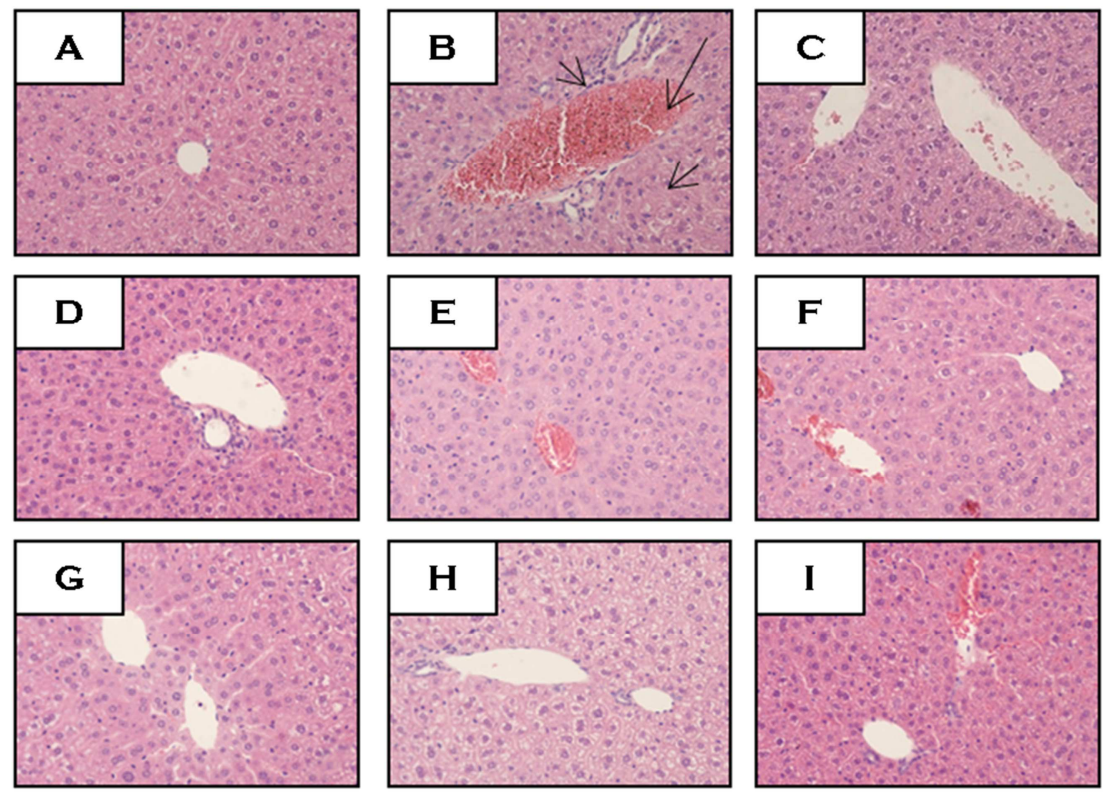

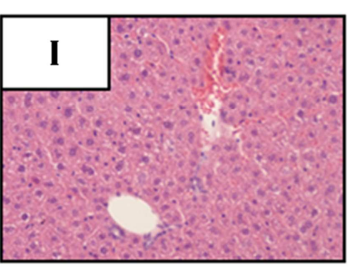

Fig. 3. Hematoxylin and eosin $(H \& E)$ staining of liver sections from mice in group (A) control, (B) acetaminophen, (C) NAC, (D) apple, (E) pear, (F) carrot, (G) broccoli, (H) cabbage, and (I) radish. Images were taken at $20 \mathrm{X}$ magnification using a microscope camera. 
these changes. APAP induced severe hepatocellular damage, with the hepatic lobules showing extensive centrilobular coagulative necrosis with increased eosinophilia. Severe hemorrhage was also observed, mostly in the hepatic lobule. The sinusoids were dilated, were heavily congested with red blood cells and lymphocytes, and the endothelia of the central veins were destroyed. Centrilobular hepatocytes showed severe ballooning degeneration. Cell boundaries were illdefined, and most nuclei were darkly stained, with the amount of heterochromatin increased at the nuclei periphery. Nuclei also showed extensive karyolysis, pyknosis, and karyorrhexis neutrophil accumulation, hemorrhage, and parenchymal cell injury (arrows, Fig. 3) and as reported previously (Blazka et al., 1996; Mossanen and Tacke, 2015). However, this damage was almost completely reversed by treatment with positive control NAC and processed apple and cabbage extracts.

Finally, these results indicate that the processed apple extract demonstrated the most antioxidant activity among the extracts tested, as it was the most effective in mitigating all parameters related to oxidative stress examined in this study. Apple extract was also shown to restore the damage induced by APAP, as demonstrated by histological analysis. Further, more detailed studies at the mechanistic level will help delineate the factors involved in the antioxidant activity of the processed apple examined in this report. Moreover, we will also try to elucidate the difference in the anti-oxidant capacity of processed and fresh fruits in future.

\section{ACKNOWLEDGEMENT}

This research was supported by Kyungpook National University Research Fund, 2017.

\section{CONFLICT OF INTEREST}

The authors declare no conflicts of interest.

\section{REFERENCES}

Alkadi H. A review on free radicals and antioxidants. Infect Disord Drug Targets. 2018. 10.2174/1871526518666180628124323: Blazka ME, Elwell MR, Holladay SD, Wilson RE, Luster MI. Histopathology of acetaminophen-induced liver changes: Role of interleukin $1 \alpha$ and tumor necrosis factor $\alpha$. Toxicologic pathology. 1996. 24: 181-189.

Boeing H, Bechthold A, Bub A, Ellinger S, Haller D, Kroke A, Leschik-Bonnet E, Muller MJ, Oberritter H, Schulze M, Stehle P, Watzl B. Critical review: Vegetables and fruit in the prevention of chronic diseases. Eur J Nutr. 2012. 51: 637-663.

Casas R, Castro-Barquero S, Estruch R, Sacanella E. Nutrition and cardiovascular health. Int J Mol Sci. 2018. 19.

Dauchet L, Amouyel P, Dallongeville J. Fruits, vegetables and coronary heart disease. Nat Rev Cardiol. 2009. 6: 599-608.

Glorieux C, Calderon PB. Catalase, a remarkable enzyme: Targeting the oldest antioxidant enzyme to find a new cancer treatment approach. Biol Chem. 2017. 398: 1095-1108.

Huang X-J, Choi Y-K, Im H-S, Yarimaga O, Yoon E, Kim H-S. Aspartate aminotransferase (ast/got) and alanine aminotransferase (alt/gpt) detection techniques. Sensors. 2006. 6: 756-782.

James LP, McCullough SS, Lamps LW, Hinson JA. Effect of nacetylcysteine on acetaminophen toxicity in mice: Relationship to reactive nitrogen and cytokine formation. Toxicol Sci. 2003. 75: 458-467.

Kasote DM, Katyare SS, Hegde MV, Bae H. Significance of antioxidant potential of plants and its relevance to therapeutic applications. Int J Biol Sci. 2015. 11: 982-991.

Kumar V, Khan AA, Tripathi A, Dixit PK, Bajaj U. Role of oxidative stress in various diseases: Relevance of dietary antioxidants. J Pharm Exp Ther. 2015. 4: 126-132.

Lee YY, Saba E, Kim M, Rhee MH, Kim H-K. Antioxidant and anti-inflammatory properties of raw and processed fruits and vegetables. Biomed Sci Let. 2018. 24: 196-205.

Leonard SS, Cutler D, Ding M, Vallyathan V, Castranova V, Shi X. Antioxidant properties of fruit and vegetable juices: More to the story than ascorbic acid. Annals of Clinical \& Laboratory Science. 2002. 32: 193-200.

Li S, Tan HY, Wang N, Cheung F, Hong M, Feng Y. The potential and action mechanism of polyphenols in the treatment of liver diseases. Oxid Med Cell Longev. 2018. 2018: 8394818.

Liu Y, Fan C, Pu L, Wei C, Jin H, Teng Y, Zhao M, Yu AC, Jiang F, Shu J, Li F, Peng Q, Kong J, Pan B, Zheng L, Huang Y. Phloretin induces cell cycle arrest and apoptosis of human glioblastoma cells through the generation of reactive oxygen species. J Neurooncol. 2016. 128: 217-223.

Lobo V, Patil A, Phatak A, Chandra N. Free radicals, antioxidants and functional foods: Impact on human health. Pharmacogn Rev. 2010. 4: 118-126. 
Lubos E, Loscalzo J, Handy DE. Glutathione peroxidase-1 in health and disease: From molecular mechanisms to therapeutic opportunities. Antioxid Redox Signal. 2011. 15: 1957-1997.

Lutz M, Fuentes E, Avila F, Alarcon M, Palomo I. Roles of phenolic compounds in the reduction of risk factors of cardiovascular diseases. Molecules. 2019. 24.

McGill MR. The past and present of serum aminotransferases and the future of liver injury biomarkers. EXCLI J. 2016. 15: 817 $-828$.

Miller HE, Rigelhof F, Marquart L, Prakash A, Kanter M. Antioxidant content of whole grain breakfast cereals, fruits and vegetables. Journal of the American College of Nutrition. 2000. 19: 312S-319S

Mossanen JC, Tacke F. Acetaminophen-induced acute liver injury in mice. Lab Anim. 2015. 49: 30-36.

Northrop JH. The kinetics of the decomposition of peroxide by catalase. J Gen Physiol. 1925. 7: 373-387.

Pandey KB, Rizvi SI. Plant polyphenols as dietary antioxidants in human health and disease. Oxid Med Cell Longev. 2009. 2: 270-278.

Sharma S, Rana S, Patial V, Gupta M, Bhushan S, Padwad YS. Antioxidant and hepatoprotective effect of polyphenols from apple pomace extract via apoptosis inhibition and nrf2 activa- tion in mice. Hum Exp Toxicol. 2016. 35: 1264-1275.

Singh K, Singh N, Chandy A, Manigauha A. In vivo antioxidant and hepatoprotective activity of methanolic extracts of daucus carota seeds in experimental animals. Asian Pac J Trop Biomed. 2012. 2: 385-388.

Syed SN, Rizvi W, Kumar A, Khan AA, Moin S, Ahsan A. In vitro antioxidant and in vivo hepatoprotective activity of leave extract of raphanus sativus in rats using ccl4 model. Afr J Tradit Complement Altern Med. 2014. 11: 102-106.

Valavanidis A, Vlachogianni T, Fiotakis C. 8-hydroxy-2'-deoxyguanosine (8-ohdg): A critical biomarker of oxidative stress and carcinogenesis. J Environ Sci Health C Environ Carcinog Ecotoxicol Rev. 2009. 27: 120-139.

Younus $\mathrm{H}$. Therapeutic potentials of superoxide dismutase. Int $\mathbf{J}$ Health Sci (Qassim). 2018. 12: 88-93.

https://doi.org/10.15616/BSL.2019.25.3.211

Cite this article as: Saba E, Lee YY, Kim M, Kim HK, Rhee MH. Comparison of the Antioxidant Activities of Various Processed Fruits and Vegetables in APAPinduced Oxidative Stress in BALB/c Mice. Biomedical Science Letters. 2019. 25: 211-217. 